Article

\title{
Preparation, Crystal and Properties of Nitrogen-Rich Energetic Salt of Bis(semicarbazide) 5, $\mathbf{5}^{\prime}$-Bitetrazole-1, $\mathbf{1}^{\prime}$-diolate
}

\author{
Zhi-Bin Zhang, Lei Yin, Xin Yin and Jian-Guo Zhang * \\ State Key Laboratory of Explosion Science and Technology, Beijing Institute of Technology, Beijing 100081, \\ China; bitZYRY@163.com (Z.-B.Z.); yinleizyyl@163.com (L.Y.); organicchemlab@163.com (X.Y.) \\ * Correspondence: zjgbit@bit.edu.cn; Tel.: +86-10-6891-8091
}

Academic Editor: Gerhard Laus

Received: 26 December 2015; Accepted: 3 February 2016; Published: 6 February 2016

\begin{abstract}
A novel energetic salt of Bis(semicarbazide) 5,5'-bitetrazole-1,1'-diolate [2(SCZ). BTO] was synthesized by using semicarbazide hydrochloride and $1 H, 1^{\prime} H-5,5^{\prime}$-bitetrazole-1,1'-diol (BTO) as raw materials, and its structure was characterized by elemental analysis, Fourier Transform infrared spectroscopy (FT-IR) spectroscopy, ${ }^{13} \mathrm{C}$ NMR spectrum and mass spectrum. The single crystal of the title salt was obtained and its structure was determined by an X-ray single-crystal diffractometer. Results show that 2(SCZ) BTO belongs to the monoclinic space group $P 22_{1} / c$ with a density of $1.685 \mathrm{~g} \cdot \mathrm{cm}^{-3}$. The thermal decomposition behavior was investigated by differential scanning calorimetry (DSC) and thermogravimetry-derivative thermogravimetry (TG-DTG) analyses, and non-isothermal kinetic parameters were also calculated. The results indicated that it has a good thermal stability with a decomposition temperature above $200^{\circ} \mathrm{C}$. The apparent activation energies were $231.2 \mathrm{~kJ} \cdot \mathrm{mol}^{-1}$ (Kissinger's method) and $228.1 \mathrm{~kJ} \cdot \mathrm{mol}^{-1}$ (Ozawa-Doyle's method), respectively, and the critical temperature of thermal explosion is $240.6^{\circ} \mathrm{C}$. The enthalpy of formation for the salt was calculated as $158.1 \mathrm{~kJ} \cdot \mathrm{mol}^{-1}$. The detonation pressure $(P)$ and detonation velocities $(D)$ of the salt were determined by using the Kamlet-Jacobs equation. The results indicated that the title salt has potential applications in the field of energetic materials.
\end{abstract}

Keywords: $\quad 1 H, 1^{\prime} H-5,5^{\prime}$-bitetrazole-1,1'-diol; energetic salt; preparation; crystal structure; detonation properties

\section{Introduction}

There is a significant interest in the development of nitrogen-rich materials, which play an important role in the field of new energetic materials due to their potential applications as promising high-energy density materials [1-4]. Recently, much effort has been focused on the research of nitrogen-rich energetic salts with high energetic properties and low sensitivity to impact and friction [5-7]. Energetic salts, especially those with excellent performance and environmental compatibility, have been considered as aerospace propellants and explosives [8-11]. From these salts, azole heterocycles and their derivatives are a unique class due to their high heats of formation, high nitrogen contents, high densities, good thermal stabilities and environmentally benign $\mathrm{N}_{2}$ as the main reaction product [12-14]. Their positive heat of formation is always attributed to the existence of a large number of $\mathrm{N}-\mathrm{N}$ and $\mathrm{C}-\mathrm{N}$ bonds, and the hydrogen bonds may also increase the density and reduce sensitivities $[15,16]$.

Since $1 H, 1^{\prime} H-5,5^{\prime}$-Bitetrazole-1,1'-diolate (BTO) was first reported by Tselinskii in 2001 [17], it has become the focal point in the energetic materials field, and the representative achievement was the synthesis of dihydroxylammonium 5,5'-bistetrazole-1,1'-diolate (TKX-50) by Fischer and Klapötke in 
2012 [18]. The nitrogen content of BTO is $65.88 \%$, and its oxygen balance is $-28.22 \%$ since introducing two hydroxyl groups in the tetrazoles, making it easy to form intra- or intermolecular bonds, which contributed to increasing the thermal and structural stability. Additionally, the hydroxyl hydrogen of BTO has a strong acid, making it easy to dissociate back into salts. Therefore, it has attracted significant attention as a good energetic anion.

In this contribution, a novel energetic salt, 2(SCZ). BTO, based on BTO and semicarbazide (SCZ), was obtained and fully characterized. The crystal structure, thermal decomposition, and heat of combustion of the salt were investigated. In addition, its detonation properties were also determined.

\section{Results and Discussion}

\subsection{Synthesis of the Energetic Salt 2(SCZ). BTO}

The starting material, $1 H, 1^{\prime} H-5,5^{\prime}$-Bitetrazole-1,1'-diolate (BTO), was prepared according to the literature [20]. As shown in Scheme 1, the salt 2(SCZ). BTO was synthesized by the reaction between BTO and SCZ in water with 1:2 molar quantities.
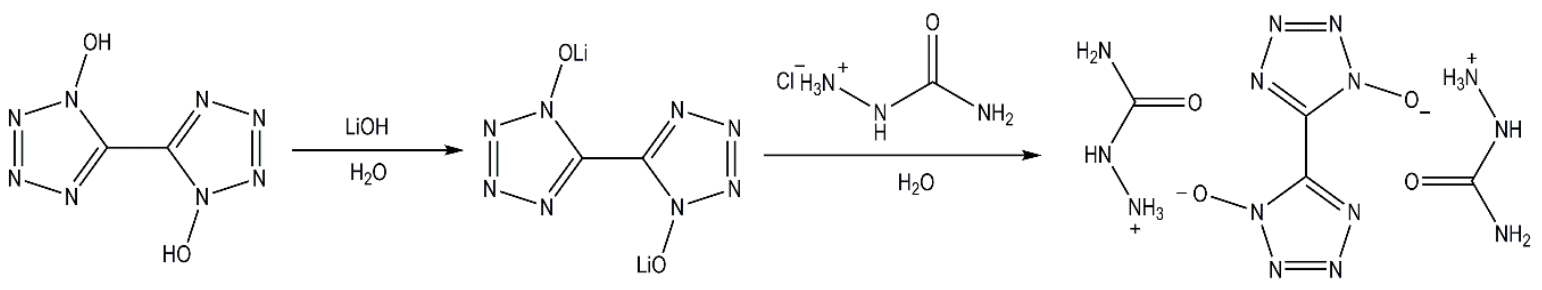

Scheme 1. Synthesis route of 2(SCZ). BTO.

\subsection{Crystal Structure}

Nitrogen-rich energetic salt 2(SCZ) BTO crystallized in the monoclinic crystal system with the space group $P 2_{1} / c$ and a crystal density of $1.685 \mathrm{~g} \cdot \mathrm{cm}^{-3}$, which contained two molecules per unit cell. Further details of the structural analysis are listed in Table 1. The molecular unit and packing diagram of salt 1 are shown in Figures 1-3. Selected bond lengths and bond angles are summarized in Table 2. The hydrogen bond parameters are given in Table 3.

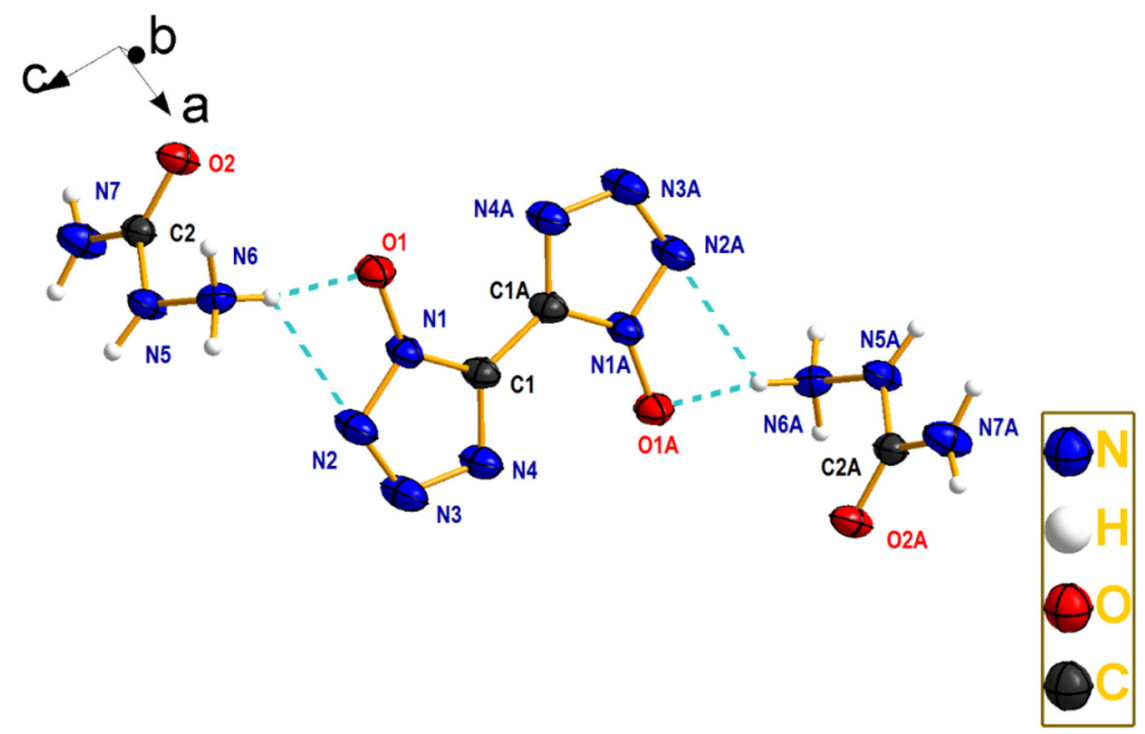

Figure 1. Molecular structure for salt 2(SCZ) BTO. The thermal ellipsoids are drawn at the 50\% probability level, the symmetry operation code is $-x+1,-y+1,-z+2$. 
Table 1. Crystal data and structure refinement details for salt 2(SCZ). BTO.

\begin{tabular}{|c|c|}
\hline Parameter & 2(SCZ) BTO \\
\hline empirical formula & $\mathrm{C}_{4} \mathrm{H}_{12} \mathrm{~N}_{14} \mathrm{O}_{4}$ \\
\hline formula mass & 320.28 \\
\hline temperature/K & $298(2)$ \\
\hline crystal system & monoclinic \\
\hline space group & $P 21 / c$ \\
\hline$Z$ & 2 \\
\hline$a / \AA$ & $10.2389(9)$ \\
\hline$b / \AA$ & $6.9576(6)$ \\
\hline$c / \AA$ & $8.9756(7)$ \\
\hline$\beta /^{\circ}$ & $99.099(2)$ \\
\hline cell volume $/ \AA^{3}$ & $631.36(9)$ \\
\hline$D_{\mathrm{c}} / \mathrm{g} \cdot \mathrm{cm}^{-3}$ & 1.685 \\
\hline$\mu(\mathrm{Mo} \mathrm{K} \alpha) / \mathrm{mm}^{-1}$ & 0.145 \\
\hline$F(000)$ & 332 \\
\hline$\theta /{ }^{\circ}$ & $3.55-25.02$ \\
\hline$h, k$ and $l$ range & -10 to $12,-8$ to $8,-10$ to 10 \\
\hline reflections collected & 3023 \\
\hline reflections unique $\left[R_{\text {int }}\right]$ & $1109[$ Rint $=0.0284]$ \\
\hline data/restraint/parameter & $1109 / 0 / 102$ \\
\hline goodness-of-fit on $F^{2}$ & 1.049 \\
\hline$R 1,[I>2 \sigma(I)]$ & 0.0381 \\
\hline $\mathrm{w} R 2,[I>2 \sigma(I)]$ & $w R 2=0.1074^{\mathrm{a}}$ \\
\hline$R 1$, (all data) & 0.0448 \\
\hline $\mathrm{w} R 2$, (all data) & $w R 2=0.1147^{\mathrm{a}}$ \\
\hline$\Delta \rho \max , \Delta \rho \min \left(\mathrm{e} \cdot \AA^{-3}\right)$ & $0.453,-0.469$ \\
\hline CCDC & 1437024 \\
\hline
\end{tabular}

Note: $w=1 /\left[s^{2}\left(F_{o}^{2}\right)+(0.0691 P)^{2}+0.2637 P\right]$, where $P=\left(F_{o}{ }^{2}+2 F_{c}^{2}\right) / 3$.
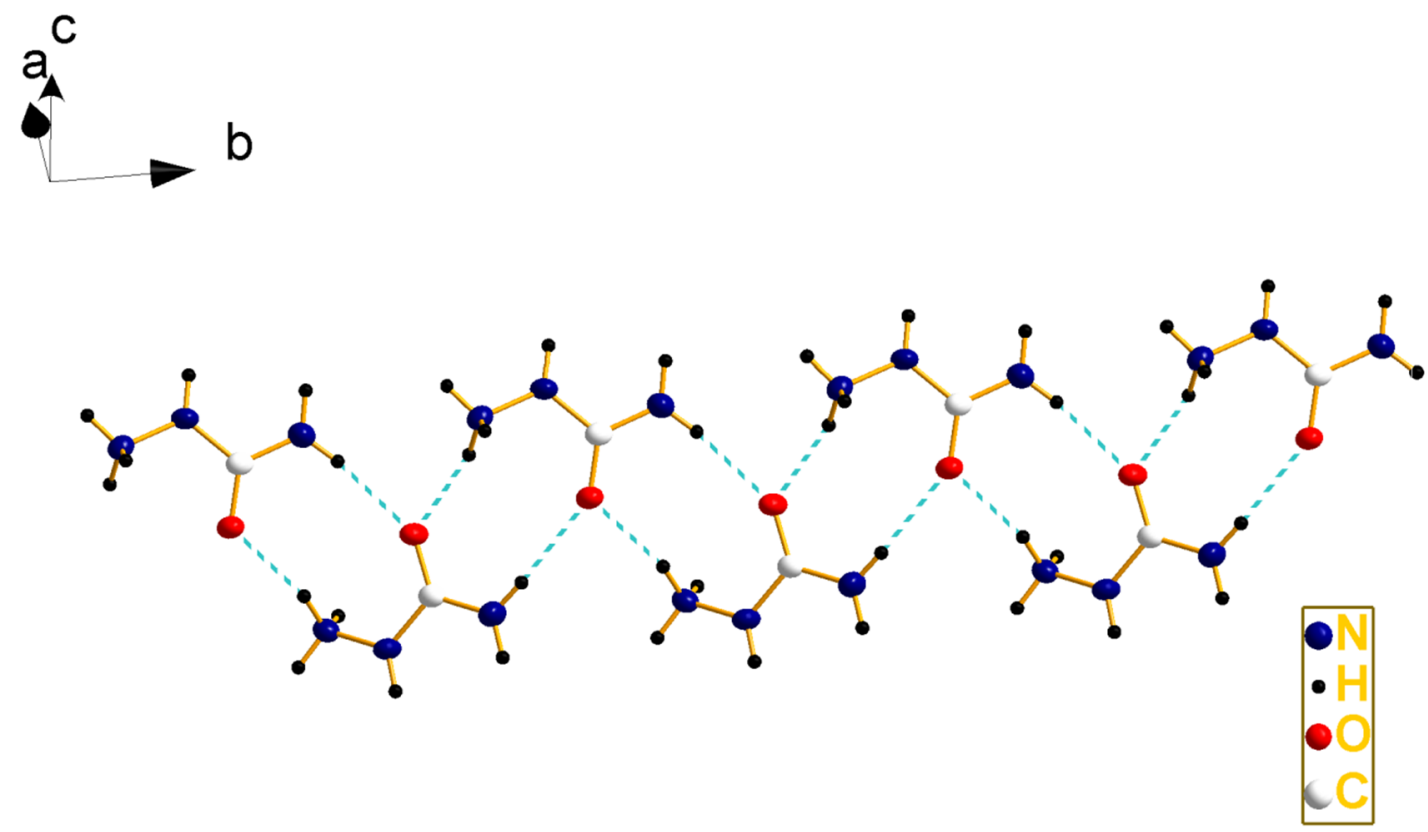

Figure 2. Ribbon motif formed through hydrogen bonding between the SCZ cations in the crystal structure. 


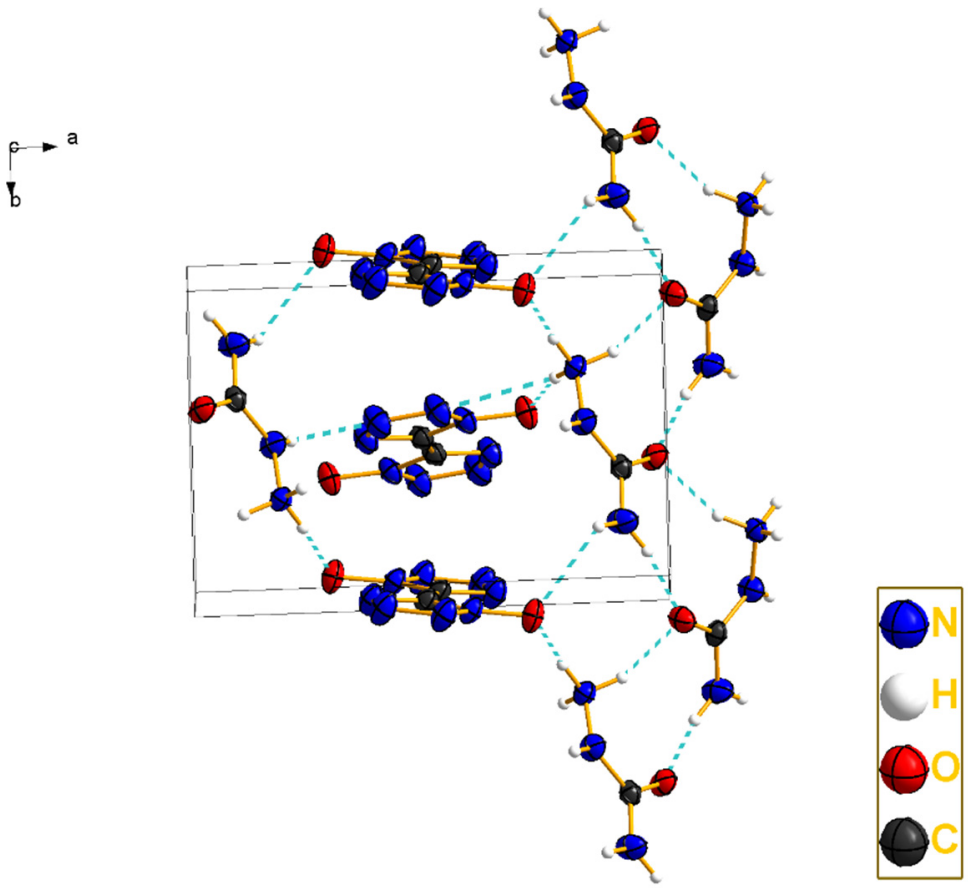

Figure 3. Packing diagram for salt 2(SCZ) BTO.

Table 2. Selected bond lengths $/ \AA$ and bond angles $/{ }^{\circ}$ for salt 2(SCZ). BTO.

\begin{tabular}{cccc}
\hline Bond & Length & Bond & Angle \\
\hline N1-O1 & $1.325(19)$ & N1-N2-O1 & $121.11(15)$ \\
N1-N2 & $1.336(2)$ & N1-C1-O1 & $129.89(15)$ \\
N1-C1 & $1.342(2)$ & N2-N1-C1 & $109.00(15)$ \\
N2-N3 & $1.315(2)$ & N3-N2-N1 & $105.53(15)$ \\
N3-N4 & $1.337(2)$ & N2-N3-N4 & $111.55(15)$ \\
N4-C1 & $1.329(2)$ & C1-N4-N3 & $105.70(16)$ \\
N5-C2 & $1.360(2)$ & C2-N5-N6 & $115.98(14)$ \\
N5-N6 & $1.421(2)$ & N4-C1-N1 & $108.21(17)$ \\
N7-C2 & $1.334(2)$ & N4-C1-C1 11 & $127.30(2)$ \\
C2-O2 & $1.238(2)$ & N1-C1-C1 1 & $124.50(2)$ \\
C1-C1 ${ }^{\# 1}$ & $1.446(4)$ & N7-C2-O2 & $123.09(16)$ \\
N6-O1 & $2.780(21)$ & N5-C2-O2 & $120.70(16)$ \\
N6-N2 & $3.261(24)$ & N7-C2-N5 & $116.11(16)$ \\
\hline
\end{tabular}

Table 3. Hydrogen bond lengths / $\AA$ and bond angles $/{ }^{\circ}$ for salt 2(SCZ). BTO.

\begin{tabular}{|c|c|c|c|c|}
\hline D-H $\cdots A$ & Length(D-H) & Length $(H \cdots A)$ & Length(D $\cdots A)$ & Angle(D-H $\cdots$ A) \\
\hline N5-H5 $\cdots$ N3 ${ }^{\mathrm{i}}$ & 0.860 & 2.136 & 2.882 & 144.92 \\
\hline N6-H6A $\cdots$ O 2 ii & 0.890 & 1.958 & 2.801 & 157.36 \\
\hline N6-H6B $\cdots$ O1 & 0.890 & 1.936 & 2.786 & 159.14 \\
\hline N6-H6B $\cdots$ N4 iv & 0.890 & 2.481 & 2.997 & 117.39 \\
\hline N7-H7A $\cdots$ O 2 v & 0.860 & 2.101 & 2.906 & 155.60 \\
\hline N7-H7B $\cdots$ O1 vi & 0.860 & 2.466 & 3.108 & 131.95 \\
\hline N6-H6C . . O1 & 0.890 & 1.906 & 2.780 & 166.85 \\
\hline N6-H6C $\cdots \mathrm{N} 1$ & 0.890 & 2.594 & 3.438 & 158.53 \\
\hline N6-H6C $\cdots$ N2 & 0.890 & 2.621 & 3.261 & 129.52 \\
\hline
\end{tabular}


As shown in Figure 1, the energetic salt 2(SCZ). BTO can be presented as the form of $\left(\mathrm{CH}_{6} \mathrm{~N}_{3} \mathrm{O}\right)_{2}{ }^{+}\left(\mathrm{C}_{2} \mathrm{~N}_{8} \mathrm{O}_{2}\right)^{2-}$, which is composed of two $\mathrm{SCZ}$ cations and a BTO anion which is formed by the combination of ionic bonds and hydrogen bonds. The two hydroxyl $\mathrm{H}$ atoms of $\mathrm{BTO}$ are lost in the reaction, forming a negative bivalence anion. While, for $\mathrm{SCZ}$ hydrochloride, the electronegativity of the N5 atom in the hydrazine group was higher than that of the $\mathrm{C} 2$ atom, the ability to attract protons for N6 was increased, which led to the transfer of the proton from BTO to the N6 position, and then formed the type of $-\mathrm{NH}_{3}{ }^{+}$cation. Finally, the $\mathrm{SCZ}$ cations and BTO anion formed a stable structure of salt 2(SCZ). BTO by electrostatic force and hydrogen bonds such as N6-H...O1 and N6-H...N2.

As shown in Table 2, in the BTO anion, the N-N bond lengths range from $1.315 \AA$ for N2-N3 to $1.337 \AA$ for N3-N4 with an average value of $1.329 \AA$, which was $0.125 \AA$ shorter than the normal $\mathrm{N}-\mathrm{N}$ bond length $(1.454 \AA)$ and $0.084 \AA$ longer than the normal N=N bond (1.245 $\AA$ ) [19]. The $\mathrm{C}-\mathrm{N}$ bonds were $1.329 \AA$ for $\mathrm{N} 4-\mathrm{C} 1$ and $1.342 \AA$ for $\mathrm{N} 1-\mathrm{C} 1$, shorter than the normal $\mathrm{C}-\mathrm{N}$ bond of $1.47 \AA$ and longer than the normal $\mathrm{C}=\mathrm{N}$ bond of $1.27 \AA$ [19], while the $\mathrm{C}-\mathrm{C}$ bond was $1.446 \AA$, which is in the normal range of $1.32 \AA$ for the $\mathrm{C}=\mathrm{C}$ bond and $1.53 \AA$ for the $\mathrm{C}-\mathrm{C}$ bond. The bond angles for the tetrazole ring of the BTO anion have a max of $129.89^{\circ}$ for $\mathrm{N} 1-\mathrm{C} 1-\mathrm{O} 1$ and $105.53^{\circ}$ for N3-N2-C1. The dihedral angle for N1-C1-C1A-N1A is $-180.00^{\circ}$, and for N4-C1-C1A-N4A it is also $-180.00^{\circ}$, which indicated the two pentagons in the BTO are coplanar in the salt. Some multiple-bond character was present, which indicated that the tetrazole ring existed as a large $\pi$-conjugated system. Additionally, it was an irregular pentagon, due to the presence of oxygen atoms [20].

The hydrogen bond is an important factor in stabilizing the crystal structure for the title salt. In this crystal, the SCZ cations are interconnected through hydrogen bonds with each other, which formed a ladder-like ribbon motif, as can be seen in Figure 2. A more detailed description for how the layers are formed not only between BTO anions and SCZ cations but also between SCZ cations through the different $\mathrm{N}-\mathrm{H}$...O hydrogen bonds from the hydroxyl and amino groups, as well as a number of $\mathrm{C}=\mathrm{O}$ bonds, is shown in Figure 3. The N6 atoms from the cations and $\mathrm{O} 1$ as well as N2 atoms from the anions are engaged in the $\mathrm{N}-\mathrm{H}$...O and $\mathrm{N}-\mathrm{H}$... $\mathrm{N}$ hydrogen bonds, which connected the $\mathrm{SCZ}^{+}$and $\mathrm{BTO}^{2-}$ tightly. At the same time, the amidinium hydrogen of the cationic SCZ moiety also forms a $\mathrm{N}-\mathrm{H}$...O hydrogen bond to a carbonyl oxygen atom of the neighboring cations. Additionally, the ribbon motifs are cross-linked by the BTO anions, which formed a structure similar to the steps on a ladder.

Details of the hydrogen bonding in the structure of the salt are summarized in Table 3. The strong intermolecular hydrogen bond between the nitrogen-rich cation and bi-tetrazole anion may make an important contribution in enhancing the thermal stability and decreasing the sensitivity of the salt.

\subsection{Thermal Decomposition and Non-Isothermal Kinetic Analysis}

The DSC and TG-DTG measurements were applied to investigate the thermal behavior of the salt. The DSC and TG-DTG curves at a linear heating rate of $5^{\circ} \mathrm{C} \cdot \mathrm{min}^{-1}$, recorded in a nitrogen atmosphere, are given in Figures 4 and 5.

There was only one exothermic process on the DSC curve for salt 2(SCZ). BTO: it decomposed at $239.9^{\circ} \mathrm{C}$ before melting, and the peak temperature was $245.3^{\circ} \mathrm{C}$. The enthalpy of this exothermic process was $96.4 \mathrm{~kJ} \cdot \mathrm{mol}^{-1}$. Correspondingly, there was a main mass loss stage in the TG-DTG curve as well. It occurred from $201.6{ }^{\circ} \mathrm{C}$ to $252.3{ }^{\circ} \mathrm{C}$ with a mass loss of $57.6 \%$, in which the largest mass rate was reached at $241.8^{\circ} \mathrm{C}$. This process showed the main exothermic decomposition of the salt. The final stage was a slow process of thermal decomposition with continuous mass loss with a final residue mass of $17 \%$. After the decomposition process the products of the salt were $\mathrm{H}_{2} \mathrm{O}, \mathrm{CO}_{2}, \mathrm{~N}_{2}$ and a small amount of residue. 


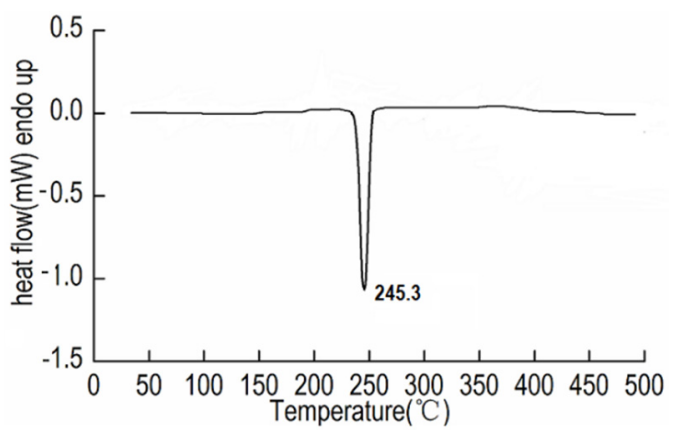

Figure 4. DSC curve of $2(\mathrm{SCZ}) \cdot \mathrm{BTO}$ at the heating rate of $5^{\circ} \mathrm{C} \cdot \mathrm{min}^{-1}$.

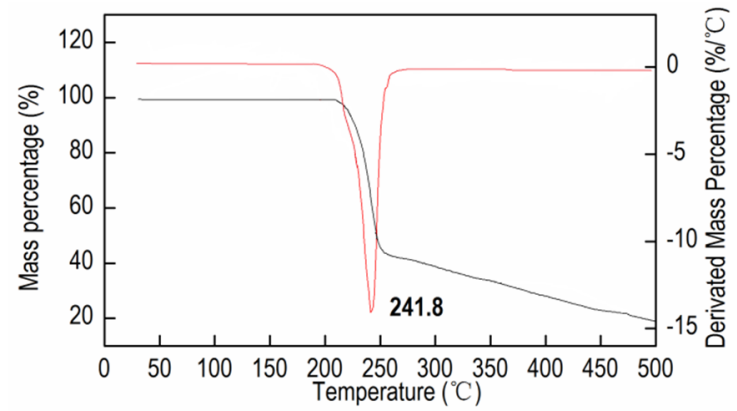

Figure 5. TG-DTG curve of 2(SCZ). BTO at the heating rate of $5^{\circ} \mathrm{C} \cdot \mathrm{min}^{-1}$.

Kissinger's method [21] and Ozawa-Doyle's method [22] are widely used to study the kinetic parameters of the rapidly exothermic process of the title salt, based on the DSC curves obtained under different heating rates. The Kissinger and Ozawa-Doyle equations are as follows:

$$
\begin{gathered}
\ln \left(\frac{\beta}{T_{p}^{2}}\right)=\ln \left(\frac{A_{k} R}{E_{k}}\right)-\frac{E_{k}}{R} \frac{1}{T_{p}} \\
\log \beta+\frac{0.4567 E_{a}}{R T_{p}}=C
\end{gathered}
$$

where $T_{\mathrm{p}}$ is the peak temperature, ${ }^{\circ} \mathrm{C} ; R$ is the gas constant, $8.314 \mathrm{~J} \cdot \mathrm{mol}^{-1} \cdot{ }^{\circ} \mathrm{C}^{-1} ; \beta$ is the linear heating rate, ${ }^{\circ} \mathrm{C} \cdot \mathrm{min}^{-1}$; and $\mathrm{C}$ is a constant.

On the basis of the peak temperatures $\left(T_{\mathrm{p}}\right)$ of the first exothermic process occurring in the DSC curves under four different heating rates $\left(5,10,15\right.$ and $\left.20^{\circ} \mathrm{C} \cdot \mathrm{min}^{-1}\right)$ of the salt, the apparent activation energy $E_{\mathrm{k}}$ and $E_{\mathrm{o}}$, pre-exponential factor $A_{\mathrm{k}}$, and linear coefficient $R_{\mathrm{k}}$ and $R_{\mathrm{o}}$ were determined and listed in Table 4. The calculated results using both methods correspond well with each other, and they are all in the normal range of kinetic parameters for the thermal decomposition of solid materials [23]. Accordingly, the Arrhenius equation of the salt can be expressed as follows ( $E$ is the average of $E_{\mathrm{k}}$ and $\left.E_{\mathrm{o}}\right): \ln k=21.21-229.65 \times 10^{3} / R T$.

\begin{tabular}{|c|c|c|c|c|}
\hline Heating rates $\left({ }^{\circ} \mathrm{C} \cdot \min ^{-1}\right)$ & 5 & 10 & 15 & 20 \\
\hline Peak temperatures $T_{\mathrm{p}}\left({ }^{\circ} \mathrm{C}\right)$ & 245.3 & 252.7 & 256.1 & 258.4 \\
\hline \multicolumn{3}{|c|}{ Kissinger's Method } & \multicolumn{2}{|c|}{ Ozawa's Method } \\
\hline $\begin{array}{c}E_{\mathrm{k}}\left(\mathrm{kJ} \cdot \mathrm{mol}^{-1}\right) \\
231.2\end{array}$ & $\begin{array}{c}\lg \left[A_{\mathrm{k}}\left(\mathrm{s}^{-1}\right)\right] \\
21.21\end{array}$ & $\begin{array}{c}R_{\mathrm{k}} \\
-0.9968\end{array}$ & $\begin{array}{c}E_{\mathrm{o}}\left(\mathrm{kJ} \cdot \mathrm{mol}^{-1}\right) \\
228.1\end{array}$ & $\begin{array}{c}R_{\mathrm{O}} \\
-0.9970\end{array}$ \\
\hline
\end{tabular}

Table 4. Peak temperatures and non-isothermal kinetic parameters of 2(SCZ) BTO.

Note: $E$ is the apparent activation energy. $A$ is the pre-exponential factor. $R$ is the linear correlation coefficient. The subscript $\mathrm{k}$ and o represent Kissinger's method and Ozawa's method, respectively. 


\subsection{Calculation of the Thermal Explosion Properties and Enthalpy of Formation}

The thermal explosion critical temperature $\left(T_{\mathrm{bp}}\right)$ is widely used to evaluate the thermal safety of energetic materials. The value of the peak temperature corresponding to $\beta \rightarrow 0\left(T_{p 0}\right)$ was obtained as $231.0^{\circ} \mathrm{C}$, according to Equation (3), where $a, b$, and $c$ are coefficients [24].

$$
T_{\mathrm{pi}}=T_{\mathrm{p} 0}+a \beta+b \beta^{2}+c \beta^{3}
$$

The corresponding critical temperature of the thermal explosion $\left(T_{\mathrm{bp}}\right)$ was calculated by Equation (4), where $R$ is the gas constant, $E$ is the value of $E_{\mathrm{k}}$ by Kissinger's method [24]. The value was $240.6^{\circ} \mathrm{C}$, respectively.

$$
T_{\mathrm{bp}}=\frac{E-\sqrt{E^{2}-4 E R T_{\mathrm{p} 0}}}{2 R}
$$

The entropy of activation $\left(\Delta S^{\ddagger}\right)$, enthalpy of activation $\left(\Delta H^{\ddagger}\right)$, and free energy of activation $\left(\Delta G^{\neq}\right)$of the decomposition reaction corresponding to $T=T_{\mathrm{p} 0}$ and $A=A_{\mathrm{k}}$ (from Kissinger's method) obtained by Equations (5)-(7) are as follows:

$$
\begin{gathered}
A=\frac{k_{\mathrm{B}} T}{h} \mathrm{e}^{\Delta S^{\neq} / R} \\
\Delta H^{\neq}=E-R T \\
\Delta G^{\neq}=\Delta H^{\neq}-T \Delta S^{\neq}
\end{gathered}
$$

where $k_{\mathrm{B}}$ is the Boltzmann constant, $1.381 \times 10^{-23} \mathrm{~J} \cdot \mathrm{K}^{-1}$, and $h$ is the Planck constant, $6.626 \times 10^{-34} \mathrm{~J} \cdot \mathrm{s}$. The calculated values are as follows: $\Delta S^{\neq}=-72.94 \mathrm{~J} \cdot \mathrm{K}^{-1} \cdot \mathrm{mol}^{-1} ; \Delta H^{\neq}=227.01 \mathrm{~kJ} \cdot \mathrm{mol}^{-1}$; $\Delta G^{\neq}=263.78 \mathrm{~kJ} \cdot \mathrm{mol}^{-1}$.

The heat of combustion and enthalpy of formation are significant characteristics for accessing the energetic properties of a new compound. The constant-volume combustion heat $\left(Q_{\mathrm{v}}\right)$ of the salt was $-10.8084 \mathrm{MJ} \cdot \mathrm{kg}^{-1}$, respectively, as measured by Parr 1104 oxygen bomb calorimetry in an oxygen atmosphere (450 psi). The bomb equation and the heat of combustion equation are as follows $\left(Q_{\mathrm{p}}\right.$ is the constant-pressure energy of combustion, accurate to 0.001 ):

$$
\begin{gathered}
\mathrm{C}_{4} \mathrm{H}_{12} \mathrm{~N}_{14} \mathrm{O}_{4}(\mathrm{~s})+5 \mathrm{O}_{2}(\mathrm{~g})=4 \mathrm{CO}_{2}(\mathrm{~g})+6 \mathrm{H}_{2} \mathrm{O}(\mathrm{l})+7 \mathrm{~N}_{2}(\mathrm{~g}) \\
\Delta H=Q_{\mathrm{p}}=Q_{\mathrm{v}}+\Delta n R T
\end{gathered}
$$

The value of $Q_{\mathrm{p}}$ was $-3446.8306 \mathrm{~kJ} \cdot \mathrm{mol}^{-1}$. Additionally, the standard enthalpy of the formation of the salt was calculated on the basis of Equations (8) and (9). With the known enthalpies of formation of the carbon dioxide, $\Delta_{f} H^{\theta}{ }_{298}\left[\mathrm{CO}_{2}(\mathrm{~g})\right]=-393.5 \mathrm{~kJ} \cdot \mathrm{mol}^{-1}$, and water, $\Delta_{f} H^{\theta}{ }_{298}\left[\mathrm{H}_{2} \mathrm{O}(\mathrm{l})\right]=-285.8 \mathrm{~kJ} \cdot \mathrm{mol}^{-1}$, the enthalpy of formation of the salt can be calculated as $158.1 \mathrm{~kJ} \cdot \mathrm{mol}^{-1}[25]$.

$$
\Delta_{\mathrm{f}} H_{298}^{\Theta}[2(\mathrm{SCZ} \cdot \mathrm{BTO})]=6 \Delta_{\mathrm{f}} H^{\Theta}\left(\mathrm{H}_{2} \mathrm{O}, \mathrm{l}\right)+4 \Delta_{\mathrm{f}} H^{\Theta}\left(\mathrm{CO}_{2}, \mathrm{~g}\right)-\Delta_{\mathrm{c}} H^{\Theta}(\mathrm{s})
$$

\subsection{Detonation Parameters}

The critical detonation parameters of energetic compounds including the detonation velocity $(D)$ and pressure $(P)$ were predicted by Empirical Kamlet-Jacobs equations [26]:

$$
\begin{gathered}
D=1.01\left(N M^{0.5} Q^{0.5}\right)^{0.5}(1+1.30 \rho) \\
P=1.558 \rho^{2} N M^{0.5} Q^{0.5}
\end{gathered}
$$


where $D$ is the detonation velocity $\left(\mathrm{km} \cdot \mathrm{s}^{-1}\right) ; P$ is the detonation pressure (GPa); $N$ is the moles of detonation gases per gram of explosive; $M$ is the average molecular weight of these gases; $Q$ is the heat of detonation $\left(\mathrm{kJ} \cdot \mathrm{kg}^{-1}\right)$; $\rho$ is the loaded density of explosives $\left(\mathrm{g} \cdot \mathrm{cm}^{-3}\right)$.

With the value for the enthalpy of formation and density of the title energetic salt, the critical detonation parameters $P$ and $D$ were determined as $23.5 \mathrm{GPa}$ and $7433.9 \mathrm{~m} \cdot \mathrm{s}^{-1}$, which were better than those of trinitrotoluene (TNT, $19.5 \mathrm{GPa}$ and $6881 \mathrm{~m} \cdot \mathrm{s}^{-1}$ ) and lower than those of cyclotrimethylenetrinitramine (RDX, 34.9 GPa and $8748 \mathrm{~m} \cdot \mathrm{s}^{-1}$ ), respectively [27].

\section{Materials and Methods}

\subsection{Materials and Physical Techniques}

All chemicals used reagents and solvents were analytically pure, and purchased commercially. Elemental analysis was performed on a flash EA 1112 full automatic trace element analyzer (Thermo Electron SPA, Waltham, MA, USA). The IR spectra were recorded with a Nexus-470 FT-IR (Nicolet, Madison, WI, USA) spectrometer using $\mathrm{KBr}$ pellet in the range of 4000 to $400 \mathrm{~cm}^{-1}$ with the resolution of $6 \mathrm{~cm}^{-1}$. The DSC and TG measurements were carried out by using a Pyris-1 differential scanning calorimeter and a Pyris-1 thermogravimetric analyzer (Perkin Elmer, Waltham, MA, USA) under dry nitrogen atmosphere with flowing rate of $20 \mathrm{~mL} \cdot \mathrm{min}^{-1}$. The energy of combustion was determined by a Parr 6200 oxygen bomb calorimeter (Parr, Moline, IL, USA) with a sample of $500 \mathrm{mg}$.

\subsection{Synthesis of the Energetic Salt 2(SCZ). BTO}

The $1 H, 1^{\prime} H-5,5^{\prime}$-Bitetrazole-1,1'-diolate dihydrate $(0.206 \mathrm{~g}, 1 \mathrm{mmol})$ was suspended in a few milliliters of water. $\mathrm{LiOH}(0.084 \mathrm{~g}, 2 \mathrm{mmol})$ was added slowly to the clear solution. The mixture was filtered after stirring in room temperature for $10 \mathrm{~min}$. Then the colorless solution was heated to boiling after adding semicarbazide hydrochloride $(0.223 \mathrm{~g}, 2 \mathrm{mmol})$ for half an hour. The solution was cooled to room temperature, and the colorless crystalline residue was filtered, $0.263 \mathrm{~g}$ ( $82 \%$ yield) was obtained. ${ }^{13} \mathrm{C}$ NMR (DMSO- $\left.d_{6}, 100 \mathrm{MHz}, \delta\right): 159.91,135.55$. IR $\left(\mathrm{KBr}, v / \mathrm{cm}^{-1}\right): 3415,3185,2656,2042$, 1695, 1596, 1528, 1399, 1222, 1171, 1140, 1046, 999, 931, 731, 645, 482. MS (ESI $\left.{ }^{-}\right), m / z: 84.0\left[\mathrm{CN}_{4} \mathrm{O}^{-}\right]$. Anal. calcd for $\mathrm{C}_{4} \mathrm{H}_{12} \mathrm{~N}_{14} \mathrm{O}_{4}$ (320.28): C 15.00, H 3.78, N 61.24; found C 14.87, H 3.81, N 61.32.

\subsection{X-ray Single-Crystal Determination}

A Bruker CCD area-detector diffractometer (Bruker, Karlsruhe, Germany) using graphite-monochromated $\mathrm{Mo} \mathrm{K}_{\alpha}$ radiation $(\lambda=0.071073 \mathrm{~nm})$ was applied for structure analyses of the target salt SCZ B BTO. Single crystal suitable for X-ray measurement was obtained by slow evaporation of solution, and a colorless crystal with dimensions of $0.45 \times 0.40 \times 0.28 \mathrm{~mm}$ was chosen for X-ray determination. The data were collected using $\pi$ and $\sigma$ scan modes at $298 \mathrm{~K}$, and the range was from $3.55^{\circ}$ to $25.02^{\circ}$. The structures were solved by direct methods using SHELXS-97 [28] and refined anisotropically on $F^{2}$ by the full-matrix least-squares technique using the SHELXL-97 programs [29]. All non-hydrogen atoms were found directly from the differential Fourier map, and the hydrogen atoms were added according to theoretical models.

\section{Conclusions}

A novel nitrogen-rich energetic salt of $1 H, 1^{\prime} H-5,5^{\prime}$-bitetrazole-1,1'-diol and semicarbazide was synthesized with a ratio of 1:2 in water solution, and the title salt was fully characterized by single-crystal X-ray diffraction. The DSC and TG-DTG analysis indicate that the salt decomposed at $239.9^{\circ} \mathrm{C}$, with the peak temperature of $245.3^{\circ} \mathrm{C}$, and the critical temperature of thermal explosion is $240.6{ }^{\circ} \mathrm{C}$. The results indicated that the salt has a good thermal stability. Non-isothermal kinetic analysis showed that the Arrhenius equation of the salt can be expressed as follows: $\ln k=21.21-229.65 \times 10^{3} / R T$. The enthalpy of formation of the salt was determined as 
$158.1 \mathrm{~kJ} \cdot \mathrm{mol}^{-1}$. The detonation pressure $(P)$ and detonation velocities $(D)$ of the salt were determined by using the Kamlet-Jacobs equation as $23.5 \mathrm{GPa}$ and $7433.9 \mathrm{~m} \cdot \mathrm{s}^{-1}$, respectively.

Based on the good thermal stability and relatively good detonation properties, the title salt 2(SCZ). BTO might have a promising future in applications as an environmentally friendly energetic material.

Acknowledgments: It should be gratefully acknowledge the financial support from the National Natural Science Foundation of China, and the project of State Key Laboratory of Science and Technology (ZDKT 12-03 \& YBKT16-04).

Author Contributions: Z.-B. Zhang conceived, designed and performed the experiments; Z.-B. Zhang and L. Yin analyzed the data; X. Yin contributed analysis tools; and Z.-B. Zhang wrote the paper.

Conflicts of Interest: The authors declare no conflict of interest.

\section{Appendix A}

The following abbreviations are used in this manuscript:

\begin{tabular}{cl}
\hline Abbreviations & Definition \\
\hline SCZ & semicarbazide \\
BTO & $1 H, 1^{\prime} H-5,5^{\prime}$-bitetrazole-1,1'-diol \\
FT-IR & Fourier Transform infrared spectroscopy \\
DSC & Differential Scanning Calorimetry \\
TG-DTG & Thermogravimetric differential heat \\
$\Delta S^{\neq}$ & The entropy of activation \\
$\Delta H^{\ddagger}$ & The enthalpy of activation \\
$\Delta G^{\ddagger}$ & The free energy of activation \\
$P$ & detonation pressure \\
$D$ & detonation velocities \\
\hline
\end{tabular}

\section{Appendix B}

CCDC-1437024 contained the supplementary crystallographic data for this paper. These data can be obtained free of charge from the Cambridge Crystallographic Data Centre via www.ccdc.cam.ac.uk/data_request/cif.

\section{References}

1. Steinhauser, G.; Klapötke, T.M. “Green” pyrotechnics: A chemists'challenge. Angew. Chem. Int. Ed. 2008, 47, 3330-3347. [CrossRef] [PubMed]

2. Klapötke, T.M.; Sabaté, C.M. Bistetrazoles: Nitrogen-rich, high-performing, insensitive energetic compounds. Chem. Mater. 2008, 20, 3629-3637. [CrossRef]

3. Göbel, M.; Karaghiosoff, K.; Klapötke, T.M. Nitrotetrazolate-2N-oxides and the strategy of N-oxide introduction. J. Am. Chem. Soc. 2010, 132, 17216-17226. [CrossRef] [PubMed]

4. Gao, H.; Shreeve, J.M. Azole-based energetic salts. Chem. Rev. 2011, 111, 7377-7436. [CrossRef] [PubMed]

5. Wang, R.H.; Xu, H.Y.; Guo, Y.; Sa, R.J.; Shreeve, J.M. Bis[3-(5-nitroimino-1,2,4-triazolate)]-Based Energetic Salts: Synthesis and Promising Properties of a New Family of High-Density Insensitive Materials. J. Am. Chem. Soc. 2010, 132, 11904-11905. [CrossRef] [PubMed]

6. Talawar, M.B.; Sivabalan, R.; Mukundan, T. Environmentally compatible next generation green energetic materials (GEMs). J. Hazard. Mater. 2009, 161, 589-607. [CrossRef] [PubMed]

7. Klapötke, T.M.; Sabaté, C.M.; Welch, J.M. Alkaline earth metal salts of 5-nitro-2H-tetrazole: Prospective candidates for environmentally friendly energetic applications. Eur. J. Inorg. Chem. 2009, 2009, 769-776. [CrossRef] 
8. Klapötke, T.M.; Sabaté, C.M.; Stierstorfer, J. Neutral 5-nitrotetrazoles: Easy initiation with low pollution. New J. Chem. 2009, 33, 136-147. [CrossRef]

9. Klapötke, T.M.; Karaghiosoff, K.; Mayer, P. Synthesis and characterization of 1,4-dimethyl-5aminotetrazolium 5-Nitrotetrazolate. Propellants Explos. Pyrotech. 2006, 31, 188-195. [CrossRef]

10. Dippold, A.A.; Klapötke, T.M.; Winter, N. Insensitive nitrogen-rich energetic compounds based on the 5,5'-Dinitro-3,3'-bi-1,2,4-triazol-2-ide anion. Eur. J. Inorg. Chem. 2012, 2012, 3474-3484. [CrossRef]

11. Wu, J.T.; Zhang, J.G.; Yin, X. Synthesis, characterization, and thermal analysis of two energetic ionic salts based on 3,4-diamino-1,2,4-triazole (DATr). Z. Anorg. Allg. Chem. 2013, 639, 2354-2358. [CrossRef]

12. Fendt, T.; Fischer, N.; Klapötke, T.M. N-rich Salts of 2-methyl-5-nitraminotetrazole: Secondary explosives with low sensitivities. Inorg. Chem. 2011, 50, 1447-1458. [CrossRef] [PubMed]

13. Klapötke, T.M. Nitrogen-rich tetrazolium azotetrazolate salts: A new family of insensitive energetic materials. Chem. Mater. 2008, 20, 1750-1763. [CrossRef]

14. Fischer, N.; Klapötke, T.M.; Stierstorfer, J. Hydrazinium nitriminotetrazolates. Z Anorg. Allg. Chem. 2011, 637, 1273-1276. [CrossRef]

15. Joo, Y.H.; Gao, H.X.; parrish, D.A.; Cho, S.G.; Goh, E.M.; Shreeve, J.M. Energetic salts based on nitroiminotetrazole-containing acetic acid. J. Mater. Chem. 2012, 22, 6123-6130. [CrossRef]

16. Wang, K.; Parrish, D.A.; Shreeve, J.M. 3-Azido-N-nitro-1H-1,2,4-triazol-5-amine-based energetic salts. Chem. Eur. J. 2011, 17, 14485-14492. [CrossRef] [PubMed]

17. Tselinskii, I.V.; Mel'nikova, S.F.; Romanova, T.V. Synthesis and reactivity of carbohydroximoyl azides: I. aliphatic and aromatic carbohydroximoyl azides and 5-substituted 1-hydroxytetrazoles based thereon. Russian J. Organ. Chem. 2001, 37, 430-436. [CrossRef]

18. Fischer, N.; Fischer, D.; Klapötke, T.M. Pushing the limits of energetic materials-the synthesis and characterization of dihydroxylammonium 5,5'-bitetrazole-1,1'-diolate. J. Mater. Chem. 2012, 22, 20418-20422. [CrossRef]

19. Fischer, N.; Izsák, D.; Klapötke, T.M.; Rappenglück, S.; Stierstorfer, J. Nitrogen-rich 5,5'-bistetrazolates and their potential use in propellant systems: A comprehensive study. Chem. Eur. J. 2012, 18, 4051-4062. [CrossRef] [PubMed]

20. Fischer, N.; Klapötke, T.M.; Reymann, M. Nitrogen-rich salts of $1 \mathrm{H}, 1^{\prime} \mathrm{H}-5,5^{\prime}$-Bitetrazole-1,1'-diol: Energetic materials with high thermal stability. Eur. J. Inorg. Chem. 2013, 2013, 2167-2180. [CrossRef]

21. Kissinger, H.E. Reaction kinetics in differential thermal analysis. Anal. Chem. 1957, 19, 1702-1706. [CrossRef]

22. Ozawa, T. A new method of analyzing thermogravimetric data bull. Chem. Soc. Jpn. 1965, 38, 1881-1886. [CrossRef]

23. Li, Z.M.; Xie, S.H.; Zhang, J.G.; Feng, J.L.; Wang, K. Two high nitrogen content energetic compounds: 3,6-diguanidino-1,2,4,5-tetrazine and its diperchlorate. J. Chem. Eng. Data 2012, 57, 729-736. [CrossRef]

24. Zhang, T.L.; Hu, R.Z.; Xie, Y. The estimation of critical-temperatures of thermal-explosion for energetic materials using nonistheramal DSC. Thermochim. Acta 1994, 244, 171.

25. Li, F.G.; Bi, Y.G.; Zhao, W.Y.; Zhang, T.L.; Zhou, Z.N.; Yang, L. Nitrogen-rich salts based on the energetic [monoaquabis (N,N-bis (1H-tetrazol-5-yl) amine)-zinc (II)] anion: A promising design in the development of new energetic materials. Inorg. Chem. 2015, 54, 2050-2057. [CrossRef] [PubMed]

26. Kamlet, K.B.; Jacobs, S.J. Chemistry of Detonations. I. A Simple Method for Calculating Detonation Properties of C-H-N-O Explosives. J. Chem. Phys. 1968, 48, 23-25. [CrossRef]

27. Zhang, Y.Q.; Guo, Y.; Joo, Y.H.; Parrish, D.A.; Shreeve, J.M. 3,4,5-Trinitropyrazole-Based Energetic Salts. Chem. Eur. J. 2010, 16, 10778-10784. [CrossRef] [PubMed]

28. Sheldick, G.M. SHELXS-97, Program for Crystal Structure Refinement; Universität of Göttingen: Göttingen, Germany, 1997.

29. Sheldick, G.M. SHELXL-97, Program for Crystal Structure Solution; Universität of Göttingen: Göttingen, Germany, 1997.

(C) 2016 by the authors; licensee MDPI, Basel, Switzerland. This article is an open access article distributed under the terms and conditions of the Creative Commons by Attribution (CC-BY) license (http:/ / creativecommons.org/licenses/by/4.0/). 